\title{
Various AKIP1 Expression Levels Affect Its Subcellular Localization but Have no Effect on NF-кB Activation
}

\author{
A. KEPROVÁ ${ }^{1,2}$, L. KOŘÍNKOVÁ ${ }^{2}$, I. KŘÍŽOVÁ ${ }^{2}$, R. HADRAVOVÁ ${ }^{1}$, F. KAUFMAN ${ }^{2}$, \\ I. PICHOVÁ ${ }^{1}$, T. RUML ${ }^{3}$, M. RUMLOVÁ ${ }^{2}$ \\ ${ }^{1}$ Institute of Organic Chemistry and Biochemistry of the Czech Academy of Sciences, Czech \\ Republic, ${ }^{2}$ Department of Biotechnology, University of Chemistry and Technology Prague, Czech \\ Republic, ${ }^{3}$ Department of Biochemistry and Microbiology, University of Chemistry and \\ Technology Prague, Czech Republic
}

Received June 21, 2018

Accepted January 14, 2019

Epub Ahead of Print March 22, 2019

\section{Summary}

A-kinase interacting protein 1 (AKIP1) has been shown to interact with a broad range of proteins involved in various cellular processes, including apoptosis, tumorigenesis, and oxidative stress suggesting it might have multiple cellular functions. In this study, we used an epitope-tagged AKIP1 and by combination of immunochemical approaches, microscopic methods and reporter assays we studied its properties. Here, we show that various levels of AKIP1 overexpression in HEK-293 cells affected not only its subcellular localization but also resulted in aggregation. While highly expressed AKIP1 accumulated in electron-dense aggregates both in the nucleus and cytosol, low expression of AKIP1 resulted in its localization within the nucleus as a free, non-aggregated protein. Even though AKIP1 was shown to interact with $\mathrm{p} 65$ subunit of NF-KB and activate this transcription factor, we did not observe any effect on NF-KB activation regardless of various AKIP1 expression level.

\section{Key words}

AKIP1 • BCA3 • Protein aggregation • NF-kappa B • Transcription regulation

\section{Corresponding author}

M. Rumlová, Department of Biotechnology, University of Chemistry and Technology Prague, Technická 5, 16628 Prague 6, Czech Republic. E-mail: Michaela.Rumlova@vscht.cz

\section{Introduction}

A-kinase interacting protein 1 (AKIP1), initially named breast cancer-associated protein 3 (BCA3), was first discovered in breast cancer cells (Kitching et al. 2003) in which it facilitated the nuclear translocation of catalytic subunit of protein kinase A (PKAc) (Sastri et al. 2005).

AKIP1 has six exons with the translational start in exon two (Kitching et al. 2003). In human cells three AKIP1 splice variants were identified: the full-length protein, one lacking the third exon ( $\triangle 3$ AKIP1), and one lacking the third and fifth exon ( $\Delta 3 \Delta 5$ AKIP1). AKIP1 has no homology to other proteins and is devoid of specific catalytic domains (Sastri et al. 2005). Coupled with the fact that AKIP1 has been shown to associate with several signaling proteins with different sub-cellular localization, it is believed that it could function as an adaptor protein (Sastri et al. 2005, Booij et al. 2016). However, its precise biological role remains unclear.

Recently, AKIP1 has been shown to bind the nuclear factor kappa B (NF- $\mathrm{B})$ p65 subunit and regulates NF- $\mathrm{KB}$ transcriptional activity (Gao et al. 2010, King et al. 2011). NF- $\mathrm{B}$ plays a key role in various biological processes, including innate and adaptive immune responses, inflammation, cell proliferation, differentiation, and survival (Hayden and Ghosh 2008).

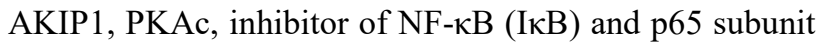
of NF- $\mathrm{NB}$ form an inactive cytosolic complex that may be 
modulated through PKA activators (Zhang et al. 2014). Phosphorylation of p65 subunit by PKA is essential for the activation and translocation of NF- $\mathrm{kB}$ p65/p50 into the nucleus where it regulates transcription of target genes (Hayden and Ghosh 2008, Gilmore 2006). AKIP1 overexpression in HEK-293 cells has been shown to modulate NF- $\mathrm{KB}$ transcriptional activity by regulating the nuclear localization of the p65 subunit as well as by promoting the phosphorylation of $\mathrm{p} 65$ by the PKAc (Gao et al. 2010, King et al. 2011). However, contradictory results have been reported regarding the role of AKIP1 in regulation of NF- $\mathrm{kB}$ p $65 / \mathrm{p} 50$-dependent transcription (Gao et al. 2006, Gao et al. 2008, Zhang et al. 2014).

In this report, we examined the effect of different levels of full-length AKIP1 expression on its cellular localization and the ability to activate NF-kB. We found that highly expressed AKIP1 is primarily localized in large aggregates in the nucleus and cytosol, but it is also present in mitochondria, while low expression of AKIP1 results in its localization predominantly within the nucleus without visible aggregation. Apart from different cellular localization patterns, neither overexpressed nor low-expressed AKIP1 was able to activate NF- $\mathrm{KB}$ transcriptional activity.

\section{Methods}

\section{Plasmids}

All DNA manipulations were carried out using standard subcloning techniques, plasmids were propagated in E. coli DH5 $\alpha$. All newly created constructs were verified by DNA sequencing. The full-length gene encoding human AKIP1 was obtained from cDNA as described in (Rumlova et al. 2014b). AKIP1 isoforms were subcloned into pCMV-HA plasmid as described in (Rumlová et al. 2018). PCR fragments were digested with appropriate restriction enzymes and ligated into $p c D N A 4 / V 5$ or $p C M V-H A$ plasmids. The $p G L 4.32-N F-$ $\kappa B-L U C$ and $h R l u c-p G L 4.70$ reporter plasmids were purchased from Promega. Vector $p G L 4.32-N F-\kappa B$-GFP was prepared using the commercially available $p G L 4.32$ $N F-\kappa B-L U C$ (Promega) and $p E G F P-C l$ (Addgene) vectors. Both vectors were digested with EcoRI and NcoI and a DNA fragment, encoding GFP from $p E G F P-C 1$, was ligated in lieu of the firefly luciferase gene into $p G L 4.32-N F-\kappa B-L U C . \quad p C M V-H A-A K I P 1$ was constructed as previously described in Rumlova et al. (2014b). Further details of the cloning strategy and full sequences of all PCR primers can be obtained from the authors upon request.

\section{Cell culture and transfection}

HEK-293 cells (Sigma Aldrich culture collection) were maintained in Dulbecco's modified Eagle's Medium (DMEM, Sigma) supplemented with $10 \%$ fetal bovine serum (Sigma) in $5 \% \mathrm{CO}_{2}$ at $37^{\circ} \mathrm{C}$. Cells were plated at a density of $3 \times 10^{5}$ cells $/ \mathrm{ml}$ one day before transfection. The following day, cells were transfected with the appropriate plasmid(s) using either polyethylenimine or the transfection reagent X-tremeGENE HP DNA according to the manufacturers' instructions (Roche). Cells were grown for $24-48 \mathrm{~h}$ post-transfection and processed further depending on the type of experiment.

\section{Generation of stable cell lines}

Stable transfectants expressing HA-AKIP1 in HEK-293 cells were prepared as previously (Rumlova $e t$ al. 2014a). For the NF-KB-GFP reporter cell line, HEK-293 cells were transfected with the $p$ GL4.32-NF$\kappa B-G F P$ plasmid containing a hygromycin resistance gene. After two weeks of hygromycin selection $(500 \mu \mathrm{g} / \mathrm{ml}$, VWR $)$, several individual clones were isolated by the cloning ring technique and expanded for further characterization. Each stable clone was stimulated with $5 \mathrm{ng} / \mathrm{ml}$ TNF- $\alpha$ (Sigma) and analyzed for GFP expression by Western blot using anti-GFP antibody or quantified by flow cytometry. Clones which demonstrated a robust increase in GFP expression upon stimulation with TNF- $\alpha$ were chosen for further experiments and designated HEK-293-NF-kB-GFP.

\section{Generation of HEK-293-Tet-off-AKIP1 cells}

The stable HEK-293 Tet-off advanced cell line (kindly provided by Dr. P. Šácha) was co-transfected with pTRE-tight-AKIP1 and pPUR plasmids at ratio 5:1 using X-tremeGENE HP DNA Transfection Reagent according to the manufacturer's instructions. Two days after transfection, the culture medium containing $20 \mathrm{ng} / \mathrm{ml}$ doxycycline (Clontech, USA) was supplemented with $0.5 \mu \mathrm{g} / \mathrm{ml}$ puromycin (Sigma-Aldrich, Germany). The selection media was changed every 3-4 days for several weeks until cell foci were visible. Individual clones were tested for AKIP1 expression by western blotting in the absence or presence of $20 \mathrm{ng} / \mathrm{ml}$ doxycycline. The positive cell line was designated as HEK-293-Tet-off-AKIP1 and maintained in the culture medium containing $20 \mathrm{ng} / \mathrm{ml}$ doxycycline. 


\section{Subcellular fractionation}

HEK-293 cells transiently or stably expressing HA-AKIP1 were seeded on $2 \times 10 \mathrm{~cm}$ Petri dishes and allowed to grow to confluence. After $48 \mathrm{~h}$ the subcellular fractionation was performed as previously described (Rumlova et al. 2014b).

\section{Western blotting}

Western blot analysis was performed as previously (Rumlova et al. 2014a). The antibody-labeled proteins were detected by West Femto Chemiluminescent Substrate (Thermo Scientific) using a LAS-3000 imager (Fujifilm). The following antibodies were used: rabbit anti-GFP (Abcam B38689); anti-mitochondrial protein antibody (Abcam Ab3298); mouse anti-HA-peroxidase (Sigma A4766); anti-p65 (Cell Signaling 8242S); anti pp65 (Cell Signaling 3033S); goat anti-rabbit (Sigma A9169); rabbit anti-IкB $\alpha$ (C-21) antibody (Santa Cruz A2510) and anti-Lamin A/C (Sigma L1293).

\section{Semi-quantitative Western blotting}

This procedure was adapted from Krizova et al. (2012). AKIP1 protein amount in different expression systems was determined by comparison with the standard curve prepared by Western blot. The standard curve was prepared from the recombinantly expressed and purified AKIP1. The samples of purified AKIP1 protein (1-2,000 ng) were separated on $12 \%$ SDS-PAGE and transferred onto nitrocellulose membrane. After overnight blocking in Blocking buffer (Blocker Casein in TBS, Thermo Scientific), the monoclonal horseradish peroxidase labelled anti-HA antibody (in dilution 1:2,000 in the Blocking buffer) was added to the membrane and incubated overnight at $4{ }^{\circ} \mathrm{C}$. The membrane was washed $3 \times 15$ min with TBS and developed using West Femto Chemiluminescent Substrate and Fusion FX7 (Vilber Lourmat). Protein band densities were quantified using Fusion CAPT Advance software (Vilber Lourmat). The linear range for purified HA-AKIP1 was determined from 1 to $500 \mathrm{ng}$. The amounts of HA-AKIP1 in different expression systems were determined by comparison of their Fusion CAPT Advance signals with those of recombinant HA-AKIP1 in a calibration curve.

\section{Luciferase reporter assay}

To determine NF- $\mathrm{kB}$ activity, HEK-293 cells stably or transiently transfected with HA-AKIP1 expression plasmid were seeded in 24-well plates and co-transfected with the $p G L 4.32-N F-\kappa B-G F P$ and
hRluc-pGL4.70 plasmids. At $24 \mathrm{~h}$ post-transfection, cells were left unstimulated or stimulated with $20 \mathrm{ng} / \mathrm{ml}$ TNF- $\alpha$ for $5 \mathrm{~h}$. The activities of both firefly and Renilla luciferases were determined with the Dual-Luciferase ${ }^{\circledR}$ Reporter Assay System (Promega) according to the manufacturer's instructions using Cytation 3 reader (Biotek).

\section{Flow cytometry}

HEK-293-NF-kB-GFP cells were seeded in 24-well plates and transfected with various amounts of pCMV-HA-AKIP1 plasmid or left untransfected. At 24-48 $\mathrm{h}$ post-transfection, cells were left unstimulated or stimulated with $20 \mathrm{ng} / \mathrm{ml} \mathrm{TNF}-\alpha$ for $5 \mathrm{~h}$ and analyzed on a BD FACSAria II (Becton Dickinson). Forward and side scatter parameters were used to eliminate dead cells and debris from analysis. 10,000 events were evaluated per sample and only single cells were used in measurements of GFP fluorescence intensity $(530 / 30 \mathrm{~nm}$ band pass filter).

\section{Immunofluorescence microscopy}

Fluorescence microscopy was carried out as previously described (Rumlova et al. 2014b, Rumlová et al. 2018). Samples were analyzed using laser scanning confocal microscope (Leica) or Olympus IX 81 microscope.

\section{Immunoelectron microscopy}

The cells were prepared and immunolabeled as previously described (Rumlova et al. 2014b). Ultrathin sections labeled with the monoclonal antibody against HA (Sigma) were examined using JOEL JEM 1011 electron microscope.

\section{Degradation of $I k B$}

HEK-293 cells were seeded in 24-well plates and transfected with the $p C M V-H A-A K I P 1$ plasmid or left untransfected. At $48 \mathrm{~h}$ post-transfection cells were left unstimulated or stimulated with $20 \mathrm{ng} / \mathrm{ml} \mathrm{TNF-} \alpha$ at the indicated times. Cells were lysed with equal volumes of SDS loading buffer at $95{ }^{\circ} \mathrm{C}$ for $10 \mathrm{~min}$, and lysates were subjected to Western blot analysis with appropriate antibodies.

\section{Immunoprecipitation}

HA-conjugated magnetic beads were used to immunoprecipitate HA-tagged AKIP1 protein from cytosolic and nuclear fractions. For immunoprecipitation 
of highly or lowly expressed HA-tagged AKIP1 protein, HEK-293 cells were treated with TNF- $\alpha(20 \mathrm{ng} / \mathrm{ml})$ or left untreated. The cytoplasmic and nuclear lysates were obtained by NE-PER nuclear and cytoplasmic extraction kit (Thermo Scientific) according to the manufacturers' instructions. Aliquots (1/5) of the obtained extracts were analyzed for the presence of the HA-AKIP, p65, pp65 and PKAc by Western blot. The rest (4/5) was incubated with anti-HA-conjugated magnetic beads (Pierce) overnight at $4{ }^{\circ} \mathrm{C}$. The immune complexes were washed three times in $1 \mathrm{ml}$ IP buffer $(20 \mathrm{mM}$ Tris, pH 7.4, $1 \mathrm{mM}$ EDTA, $250 \mathrm{mM} \mathrm{NaCl}, 3.5 \mathrm{mM} \mathrm{MgCl}_{2}$ ). The bound proteins were eluted with an equal volume of SDS loading buffer at $95^{\circ} \mathrm{C}$ for $10 \mathrm{~min}$. The samples were resolved by SDS-PAGE (10-15\%) and analyzed by Western blotting.

\section{Statistical analysis}

All results are depicted as mean \pm SD from three independent experiments. Statistical analysis was performed with unpaired Student's t-test using GraphPad Prism 7. Data was considered statistically significant for $p<0.05$.

\section{Results}

To study biological function of full-length AKIP1, we sought whether the different AKIP1 distribution in cells might be affected by the choice of experimental system. To address this question, we employed two distinct expression systems. First, we used transient expression under CMV promoter control resulting in high level of AKIP1 protein, termed as highly expressed AKIP1 (Fig. 1, left panel). Second, we used previously reported HEK-293 cells stably producing HA-AKIP1at low level (Rumlova et al. 2014a), termed as lowly expressed AKIP1 (Fig. 1, right panel). Quantification of the AKIP1 amount in these two expression systems was carried out by semi-quantitative Western blot, using a recombinant, purified AKIP1 protein for calibration. The difference in the expression level between these two systems was found to be 120 times: standard transfection procedure of $p C M V-H A-A K I P 1$ vector at the DNA concentration $1 \mu \mathrm{g}$ per $3 \times 10^{5}$ cells led to the expression of about $335 \mathrm{ng} / \mathrm{ml}$ of AKIP1 per ml whereas lowly overexpressed AKIP1 in the stably-transfected cell line resulted in $2.8 \mathrm{ng} / \mathrm{ml}$ of AKIP1.

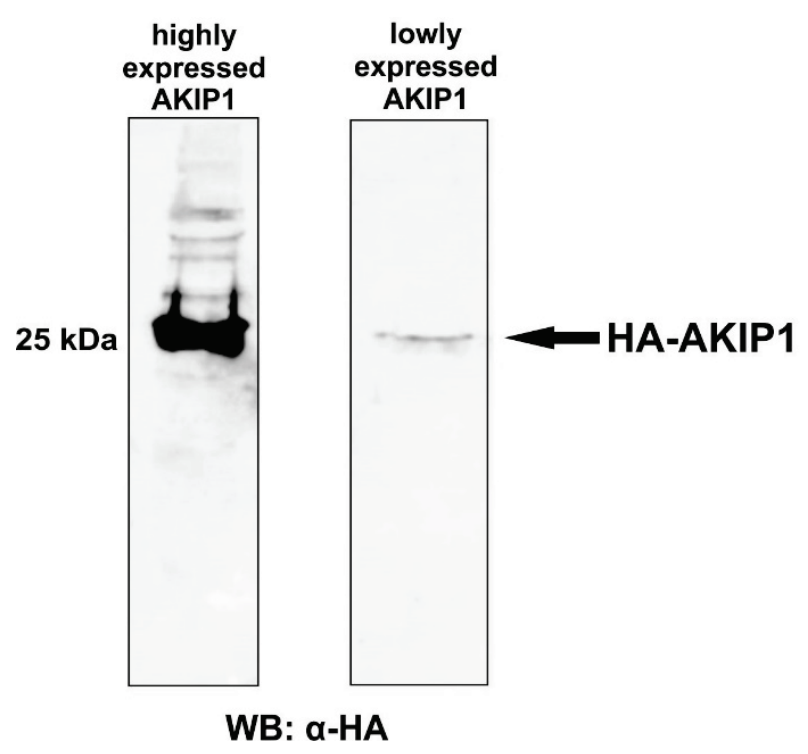

Fig. 1. AKIP1 levels in two different expression systems. Representative Western blot of highly (left panel) and lowly expressed AKIP1 (right panel) in HEK-293 cells visualized with anti-HA monoclonal antibody.

Highly expressed AKIP1 is localized in the cytosol, nucleus and mitochondria

To compare subcellular localization of highly and lowly expressed HA-AKIP1, first we employed fluorescence microscopy. HEK-293 cells were transiently transfected by $H A-A K I P 1$, and immunostained $24-48 \mathrm{~h}$ later with FITC-labelled anti-HA antibody. As shown in Fig. 2A, highly expressed HA-AKIP1 was localized mostly with a speckles-like appearance in the nucleus and the cytosol. To analyze subcellular localization in more detail, cells lysate of highly expressing AKIP1 was separated by differential low-speed centrifugations, as described earlier (Rumlova et al. 2014b, Langerova et al. 2017). The resulting fractions, including the cytosol, the nucleus and a fraction containing large membrane organelles, which we designated as a crude mitochondrial fraction, were analyzed by Western blotting using anti-HA antibody (Fig. 2B). Highly expressed AKIP1 was found to be preferentially localized in the nuclear fraction but some of the overexpressed AKIP1 was also detected in the cytosolic and crude mitochondrial fractions (Fig. 2B). To verify that highly expressed AKIP1 is associated with mitochondria, we purified the crude mitochondrial fraction further through a discontinuous Optiprep gradient. Western blot analysis of individual Optiprep gradient fractions revealed association of AKIP1 with purified mitochondria, which were identified by an anti-mitochondrial (mito) protein 
antibody (Fig. 2C). To confirm the subcellular localization of AKIP1, we employed immunogold transmission electron microscopic (TEM) analysis. As shown in Fig. 2D, highly expressed AKIP1 was found as part of larger electron-dense aggregates in the cytosol and nucleus as well as associated with mitochondria.

A
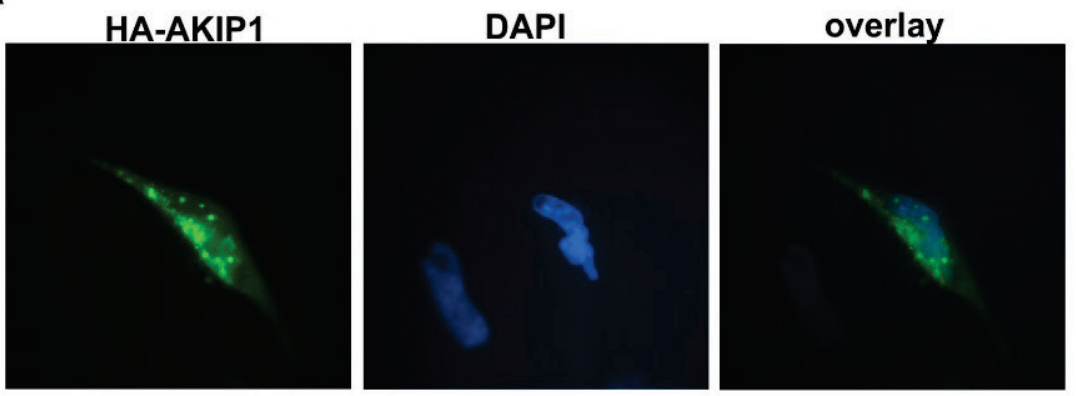

B

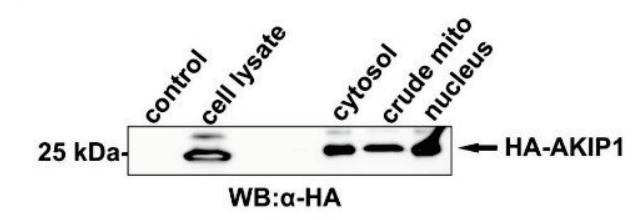

C

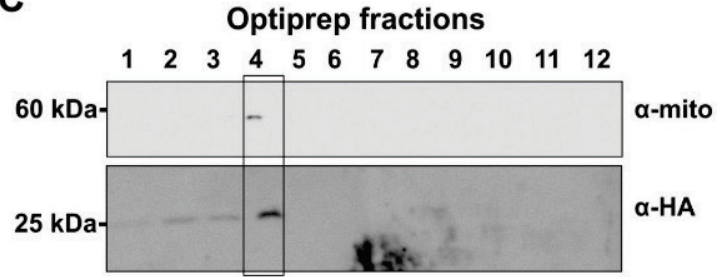

D

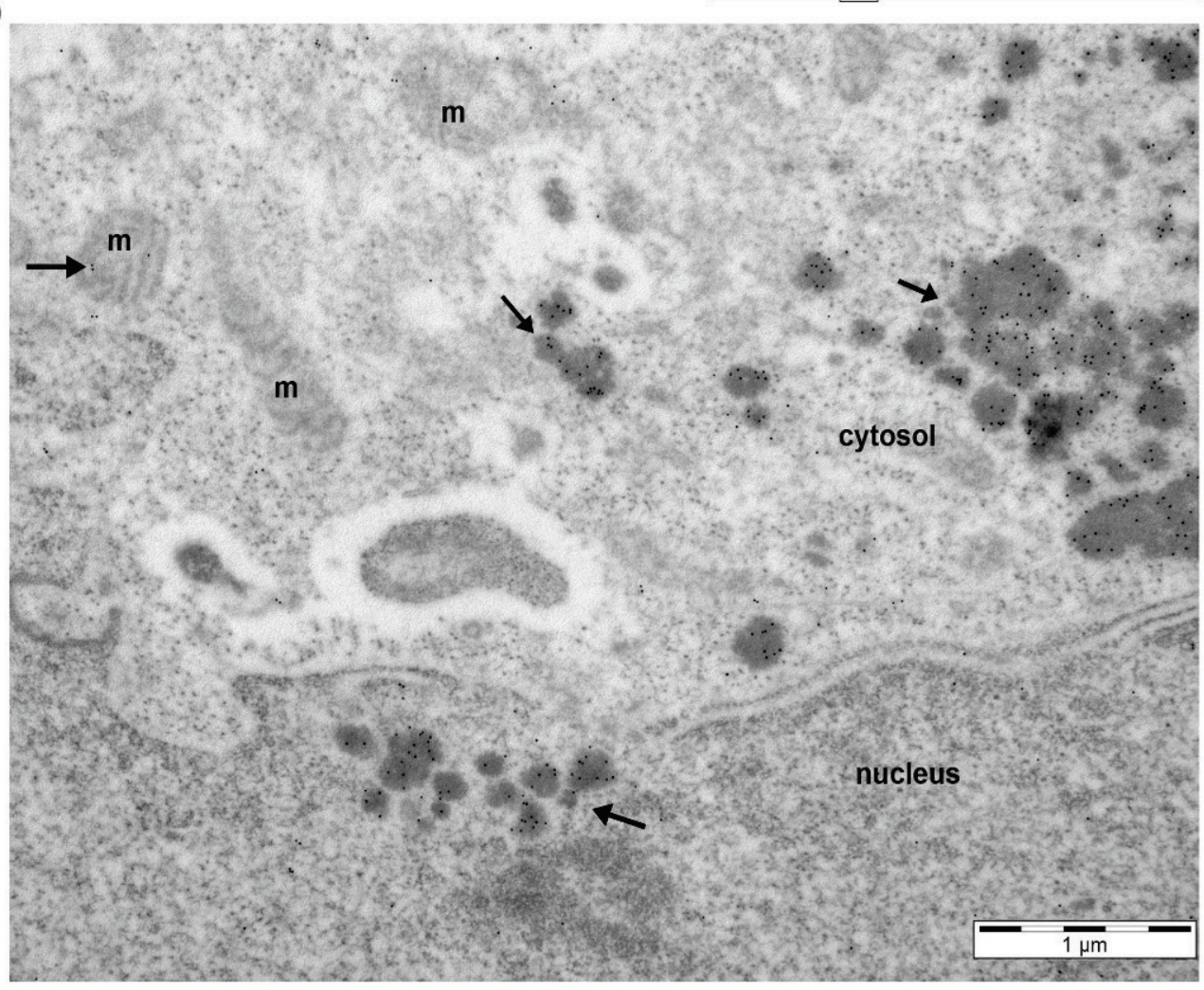

Fig. 2. Subcellular localization of highly expressed AKIP1. (A) Immunofluorescence images of HEK-293 cells highly expressing AKIP1 stained with stained with 4,6-diamidino-2-phenylindole (DAPI, blue) and HA-FITC (green) antibody. (B) Western blot analysis of subcellular fractionation of HEK-293 cells overexpressing HA-AKIP1 showing cytosolic, nuclear and crude mitochondrial fractions. (C) Centrifugation analysis of purified mitochondria from HEK-293 cells highly expressing HA-AKIP1. Fractions from the Optiprep gradient (labeled 1-12) were subjected to SDS-PAGE and analyzed using Western blotting with the anti-mitochondrial (mito) protein antibody and anti-HA antibody. (D) Representative TEM image showing HA-antibody-linked gold particles in the whole lysate of HEK-293 cells highly expressing HA-AKIP1. Immunogold staining of highly expressed AKIP1 (indicated by arrows) was localized as a part of larger aggregates in the nucleus, cytoplasm and mitochondria. The letter $(m)$ indicates mitochondria. 
A
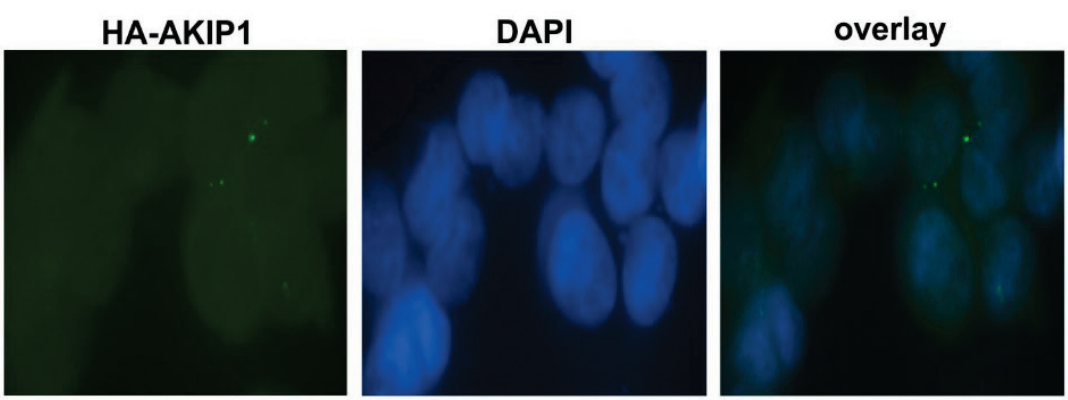

B

C

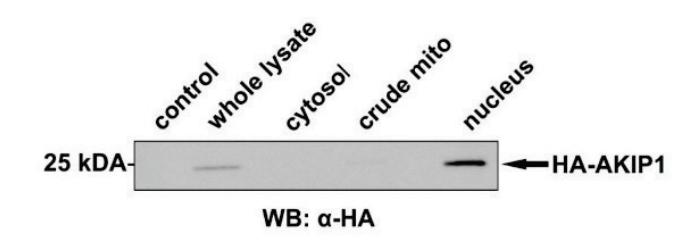

Optiprep fractions

12344567899101112

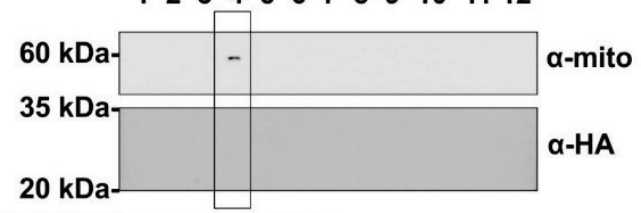

D

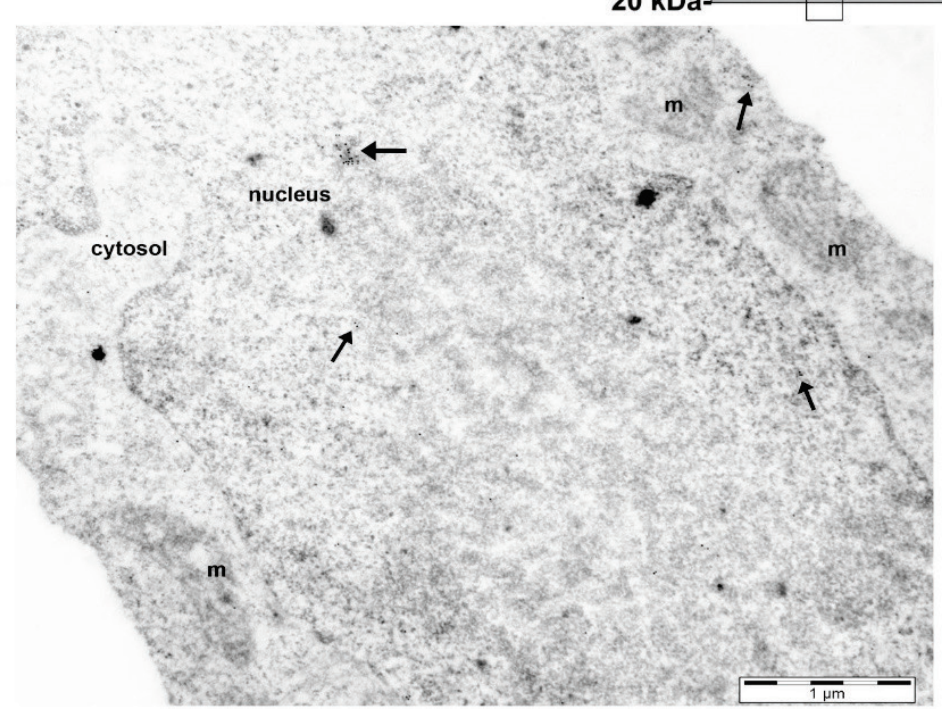

Fig. 3. Subcellular localization of lowly expressed AKIP1. (A) HEK-293 cells stably expressing HA-AKIP1 were co-stained with anti HA-FITC antibody and DAPI and visualized using confocal microscopy. (B) Western blot analysis of subcellular fractionation of HEK-293 cells stably expressing HA-AKIP1. (C) The Optiprep gradient of purified mitochondria from HEK-293 cells stably expressing HA-AKIP1. Fractions from the Optiprep gradient (labeled 1-12) were analyzed using Western blotting with the anti-mitochondrial (mito) protein antibody and anti-HA antibody. (D) Immunogold detection of lowly expressed HA-AKIP1 in HEK-293 cells. The letter (m) indicates mitochondria. The arrows indicate HA-antibody-linked gold particles.

Lowly expressed HA-AKIP1 is accumulated in the nucleus

Next, we determined the subcellular localization of HA-AKIP1 expressed at low level. To do so, we used a previously established HEK-293 cell line stably expressing low amount of HA-AKIP1 (Rumlova et al. 2014b, Rumlova et al. 2014a) and carried out the same experiments as described above. The expression of HA-AKIP1 in this system was much lower as documented by fluorescent microscopy and Western blot analysis (Fig. 3A, B). Immunochemical analysis of separated subcellular fractions of HEK-293 cells stably expressing HA-AKIP1 showed its presence only in the nucleus (Fig. 3B). In comparison to transient transfection, lowly expressed HA-AKIP1 was not detected in the cytosolic fraction or purified mitochondria. Immunogold transmission electron microscopy confirmed the presence of lowly expressed AKIP1 within the nucleus. However, in contrast to highly expressed AKIP1, no protein aggregates were observed (Fig. 3D).

Neither highly nor lowly expressed AKIP1 affects $N F-\kappa B$ transcriptional activity

Next, we sought to determine the effect of AKIP1 levels on NF- $\kappa$ B activation. Thus, we used a dual-luciferase reporter (DLR) assay, which allows the 
sequential measurement of two reporters in a single sample. The system is based on transfection with $p G L 4.32-N F-\kappa B-L U C$ reporter vector, encoding a firefly luciferase gene under the transcriptional control of an $\mathrm{NF}-\kappa \mathrm{B}$ enhancer sequence and a hRluc-pGL4.70 vector, encoding Renilla luciferase under constitutive promoter used for normalization of transfection efficiency. In our experiments, HEK-293 cells were co-transfected with these two, reporter and normalization plasmids and the expression vector pCMV, either empty or encoding HA-tagged AKIP1. Twenty-four hours post-transfection the cells were left unstimulated or stimulated with TNF- $\alpha$ (known to induce NF- $\mathrm{BB}$ activation) for $5 \mathrm{~h}$ and then assayed for both luciferases activities. The expression of the AKIP1 protein was confirmed by Western blot analysis (Fig. 4A). In non-stimulated cells, the highly expressed AKIP1 showed no significant effect on NF- $\kappa B$ activation $(p>0.05)$ compared to the empty vector designated as a control (Fig. 4B). Similarly, TNF- $\alpha$ stimulation of HA-AKIP1 transfected cells had an insignificant effect $(p>0.05)$ on NF- $\kappa$ B activation (Fig. 4C). To analyze the effect of lowly expressed AKIP1 on NF- $\mathrm{B}$ activation, HEK-293 cells stably producing HA-AKIP1 were co-transfected with both luciferase-containing plasmids for the DLR assay. HA-AKIP1 expression in HEK-293 cells was confirmed by Western blot analysis (Fig. 4D). At $24 \mathrm{~h}$ post-transfection, cells were left unstimulated or stimulated with TNF- $\alpha$ for $5 \mathrm{~h}$, and both luciferase activities were determined. No significant differences in $N F-\kappa B$ activity were observed $(p<0.05)$ either for the unstimulated (Fig. 4E) or TNF- $\alpha$ stimulated cells (Fig. 4F). These findings suggest that neither highly nor lowly expressed AKIP1 is involved in the regulation of $\mathrm{NF}-\kappa \mathrm{B}$ transcriptional activity. The same result, i.e. no effect of highly expressed AKIP1 on NF- $\mathrm{B}$ activation was obtained in HeLa cells (data not shown).

To exclude that NF- $\kappa \mathrm{B}$ activation might be AKIP1 concentration specific, we established Tet-off (tetracycline-repressed) system in HEK-293 cells, in which the expression of AKIP1 is regulated by presence/absence of doxycycline (DOX) (Fig. 4G). Using this system, we studied the effect of NF- $\mathrm{BB}$ activation in AKIP1 concentration dependent manner. However, similarly to the cells expressing AKIP1 either at low or high levels, none of the AKIP1 concentrations reached in this experiment

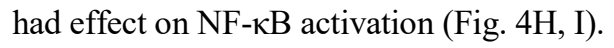

To further confirm the results obtained from the DLR assay, we generated a novel HEK-293-GFP reporter cell line for monitoring the NF- $\mathrm{KB}$ activation in response to the AKIP1 expression. HEK-293 cells were transfected with a modified $p G L 4.32-N F-\kappa B$ expression plasmid, in which the gene encoding firefly luciferase was replaced by the one encoding GFP. In this system GFP expression starts only upon NF- $\kappa \mathrm{B}$ activation (Fig. 5A). In our experiments, HEK-293-NF-кB-GFP cells were co-transfected with various amounts of plasmid encoding HA-AKIP1 (Fig. 5B) and the cells expressing GFP were quantified by flow cytometry. In the co-transfected non-stimulated cells, no significant changes $(p<0.05)$ in $\mathrm{NF}-\kappa \mathrm{B}$ activation were observed in comparison with non-transfected cells, termed as a control (Fig. 5C). Similarly, no effect on NF- $\mathrm{BB}$ activity was observed in TNF- $\alpha$ stimulated transfected or non-transfected cells (Fig. 5C). In accordance with the results obtained by the DLR assay, these findings also suggest that AKIP1 is not involved in the regulation of $\mathrm{NF}-\kappa \mathrm{B}$ transcriptional activity.

\section{AKIP1 does not affect $I \kappa B$ degradation}

As the activation of $\mathrm{NF}-\kappa \mathrm{B}$ is primarily initiated by $I \kappa \mathrm{B} \alpha$ degradation, we also tested whether the presence of AKIP1 might change I $\kappa \mathrm{B} \alpha$ cellular level. HEK-293 cells were transfected with a plasmid encoding HA-AKIP1 or left untransfected. At $48 \mathrm{~h}$ posttransfection, unstimulated and TNF- $\alpha$ stimulated cells were harvested at time intervals, and degradation of $\mathrm{I} \kappa \mathrm{B} \alpha$ was examined by Western blot. No effect of AKIP1 expression on $\mathrm{I} \kappa \mathrm{B} \alpha$ degradation was observed in comparison to the TNF- $\alpha$-stimulated control cells (data not shown). This result supports our observation that overexpressed AKIP1 did not affect NF- $\kappa$ B activation.

\section{AKIP1 associates with activated $N F-\kappa B$ in nucleus}

To analyze the ability of AKIP1, NF- $\kappa$ B and PKAc proteins to associate in AKIP1 concentration manner, we carried out co-immunoprecipitation experiments from the lysates of nuclear and cytosolic fractions. Both extracts were subjected to immunoprecipitation with anti-HA magnetic beads followed by Western blot analysis with appropriate antibodies. The presence and purity of both fractions were determined using specific antibodies recognizing $\alpha$-tubulin, used as a cytosolic marker, and Lamin A/C, used as the nuclear marker. Highly expressed AKIP1 interacted with both p65 and PKAc in the cytosol of unstimulated cells (Fig. 6A, left panels, lane 3). In contrast, in TNF- $\alpha$ stimulated cells, where majority of 
$\mathrm{NF}-\mathrm{\kappa B}$ was activated and re-localized into the nucleus, only the AKIP1-PKAc interaction was detected in the cytosolic fraction (Fig. 6A, left panels, lane 4). Activated and phosphorylated p65 subunit of NF- $\mathrm{kB}$ upon TNF- $\alpha$ stimulation co-immunoprecipitated with AKIP1 in the nuclear fraction (Fig. 6A, right panel, lane 8).
A

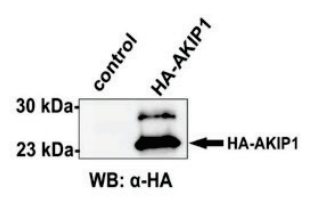

D

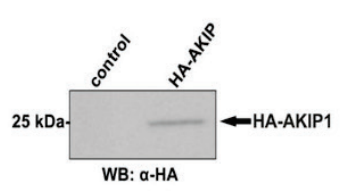

B

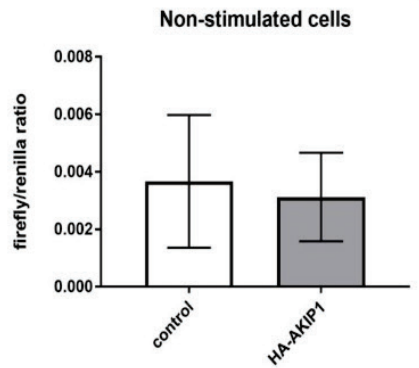

E

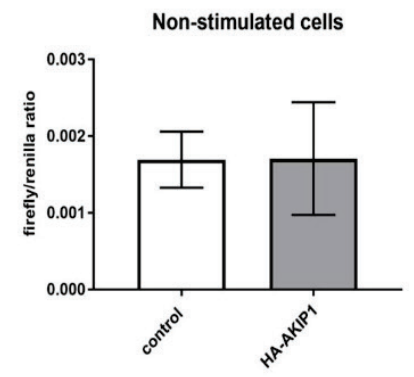

C

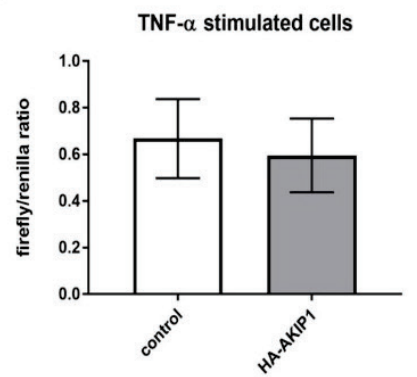

$\mathbf{F}$

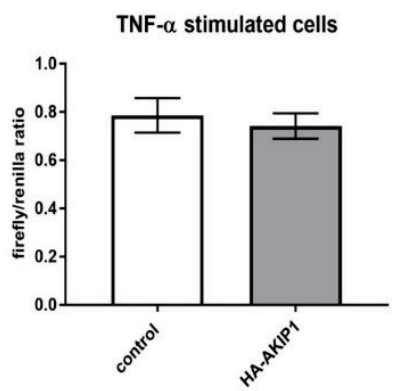

G Induced:

$\underline{\text { Un-induced: }}$
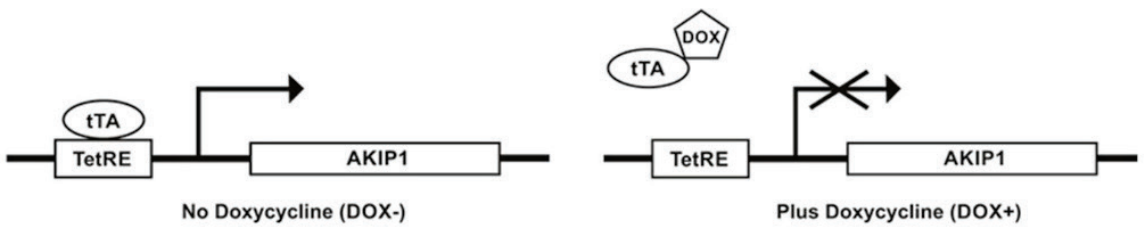

H
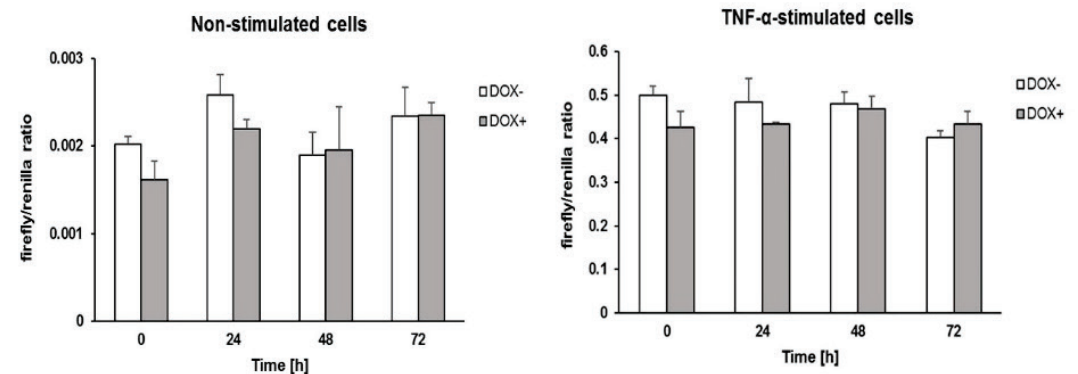

I
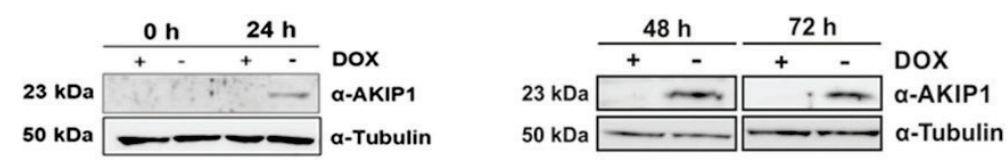

Fig. 4. The effect of AKIP1 expression on NF-KB activity assessed by DLR assay. HEK-293 cells were transfected with $p C M V-H A-A K I P 1$ (A-C) or HEK-293 cells stably producing low amount of HA-AKIP1 were used (D-F). Both expression systems were then co-transfected with $p G L 4.32-N F-K B$-LUC and $h R / u C-p G L 4.70$ vectors. HEK-293 cells transfected with both luciferases-encoding vectors and empty pCMV-HA vector were used as a control. (A, D), Expression of HA-AKIP1 was determined by Western blot analysis using the monoclonal anti-HA antibody. At $48 \mathrm{~h}$ post the first transfection, the cells were left unstimulated (B, E) or stimulated with $20 \mathrm{ng} / \mathrm{ml}$ TNF-a (C, F), and $5 \mathrm{~h}$ later the both luciferases activities were determined by DLR assay. Data are expressed as the mean \pm SD from three independent experiments. The scheme of Tet-off (tetracycline-repressed) system in HEK-293 cells for AKIP1 expression regulated by presence/absence of doxycycline (DOX) (G). The cells were co-transfected with $p G L 4.32-N F-k B-L U C$ and $h R / u c-p G L 4.70$ vectors. At indicated time post induction, the cells were left unstimulated $(\mathbf{H}$, left panel) or stimulated with $20 \mathrm{ng} / \mathrm{ml} \mathrm{TNF}-\mathrm{a}$ (H, right panel), and $5 \mathrm{~h}$ later the both luciferases activities were determined by DLR assay. The AKIP expression was detected at indicated time by rabbit anti-AKIP1 antibody (house made) (I). 
Even though lowly expressed AKIP1 was localized primarily in the nucleus, we used the cytoplasmic fraction to control antibodies specificity in co-immunoprecipitation experiments. No co-immunoprecipitation was observed in cytosolic fractions (Fig. 6B, left panels). In the nuclear fraction of TNF- $\alpha$ stimulated cells, we observed a profile very similar to the one of highly expressed AKIP1. As shown in Fig. 6B, lane 12, lowly expressed AKIP1 also immunoprecipitated with the phosphorylated (S536) p65 subunit of NF-kB.

\section{Effect of AKIP1 isoform on $N F-\kappa B$ activation}

To analyze the ability of AKIP1 isoforms to

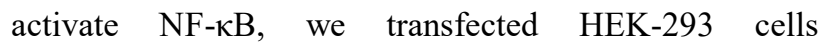
with vectors encoding HA-tagged AKIP1-truncated isoforms (Fig. 7A). All isoforms were well expressed with no apparent effect on endogenous levels of p65 subunits of NF- $\kappa$ B or PKAc, as observed by Western blot (Fig. 7B). The impact of AKIP-1 isoforms on NF- $\kappa$ B activation was then monitored using DLR. As shown in Fig. 7C, D, none of the AKIP1 isoforms enhanced activation of NF- $\mathrm{BB}$. However, apart from full-length AKIP1, all its isoforms decreased the activation of NF- $\kappa B$. Whether or not this observation is of biological importance remains to be elucidated.
A

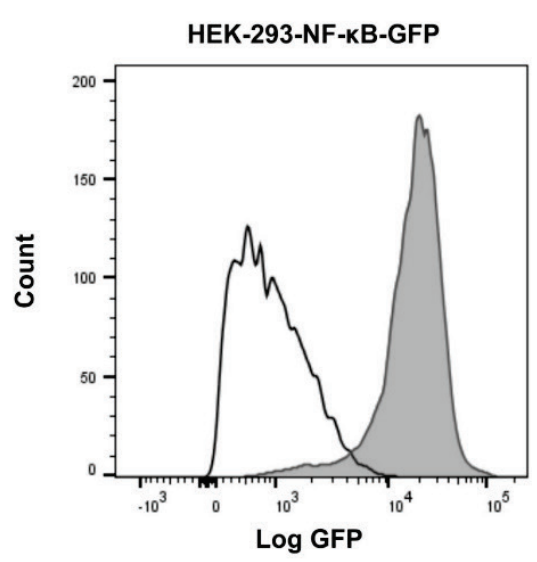

C

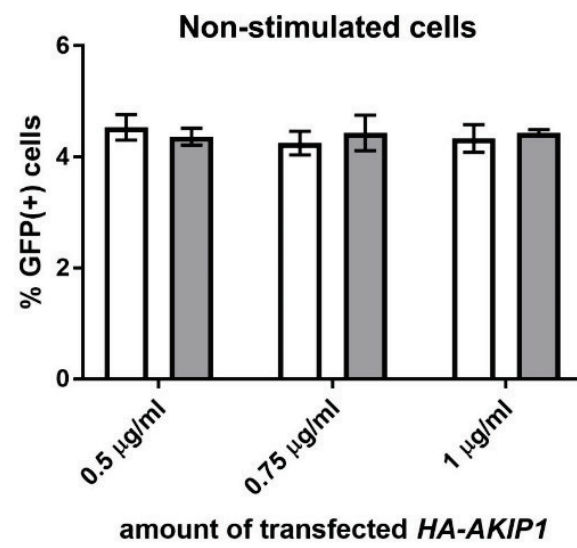

B
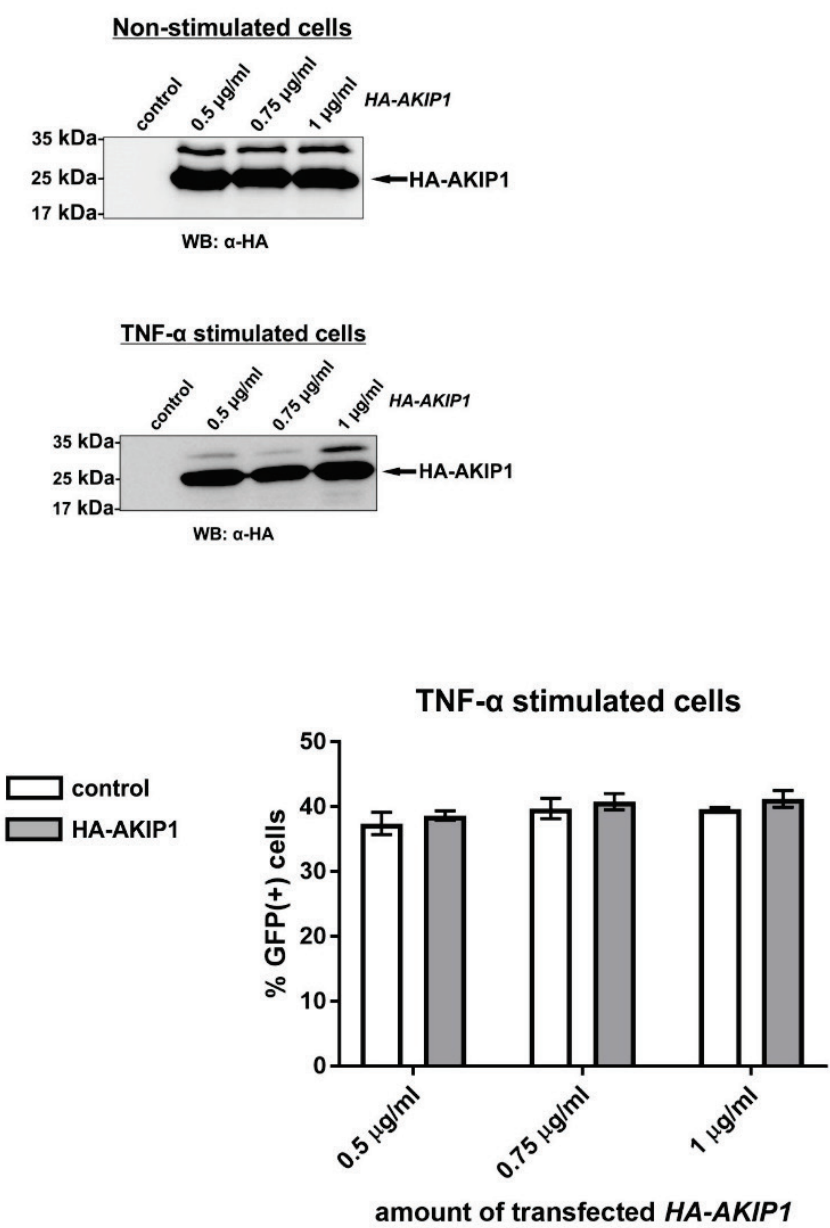

Fig. 5. Construction of new GFP reporter HEK-293 cell line (HEK-293-NF-KB-GFP) and its usage in determination of the effect of dose-dependent expression of AKIP1 on NF-KB activation (A) Flow cytometry verification of HEK-293-NF-KB-GFP. The target cell population was gated using SSC-A versus FSC-A dot plot and then represented in a histogram depicting GFP fluorescence. Non-stimulated cells are shown in white, stimulated cells are shown in grey. (B) HEK-293-NF-KB-GFP cells were transfected with various amounts of HA-AKIP1 $(0.5-1 \mu \mathrm{g} / \mathrm{ml})$, and $24 \mathrm{~h}$ later, the cells were left unstimulated or stimulated with $20 \mathrm{ng} / \mathrm{ml}$ TNF-a and protein expression was verified by Western blot analysis using anti-HA antibody. (C) Samples from (B) were analyzed on a BD FACSAria II and data was expressed as a mean of triplicates with SD error bars. 


\section{Discussion}

Early evidence demonstrated that AKIP1 is highly expressed in breast cancer tissues, while its relatively low expression levels were found in normal tissue (Kitching et al. 2003). However, later experiments showed that AKIP1 expression is extremely low even in breast cancer cell lines such as MDA-MB-231 (Sastri et al. 2013), previously reported to express a high amount of endogenous AKIP1 (Gao et al. 2010). Therefore, the majority of data on AKIP1 localization and its role in cells was obtained based on its overexpression in HEK-293 or HeLa cells (Sastri et al. 2005, Gao et al. 2008, Gao et al. 2010, King et al. 2011, Yao et al. 2017, Leung and Ngan 2010).

A

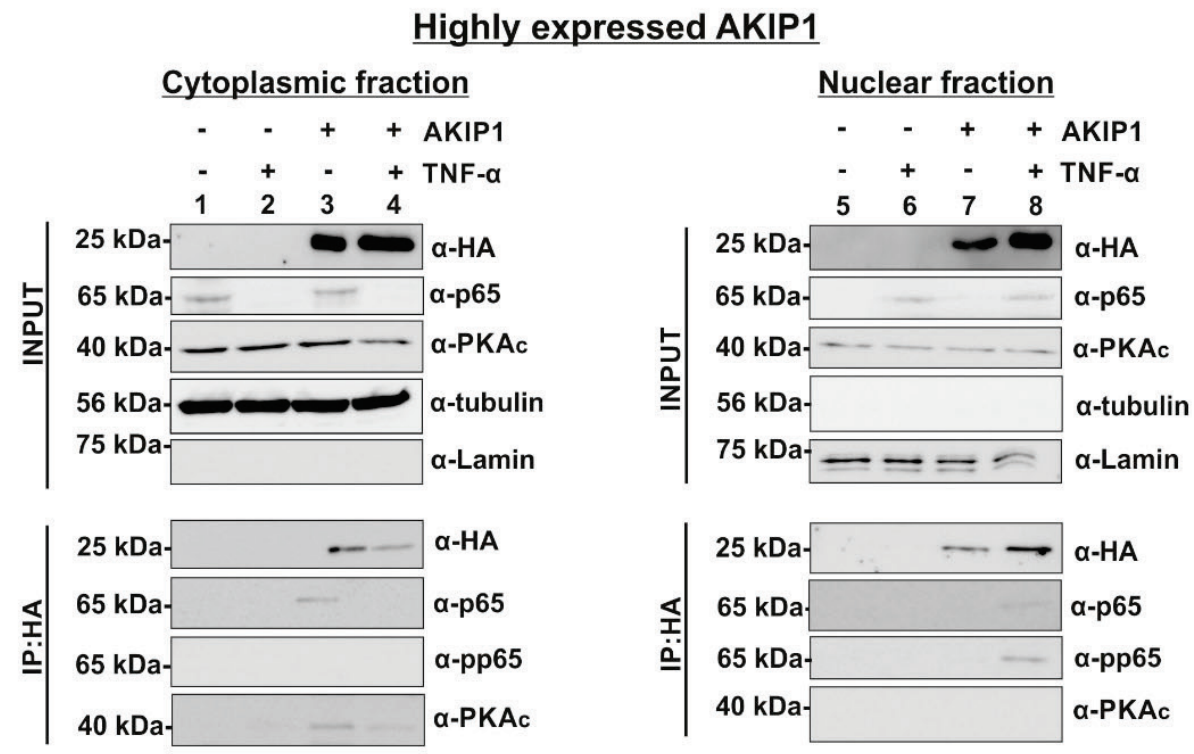

B

\section{Lowly expressed AKIP1}

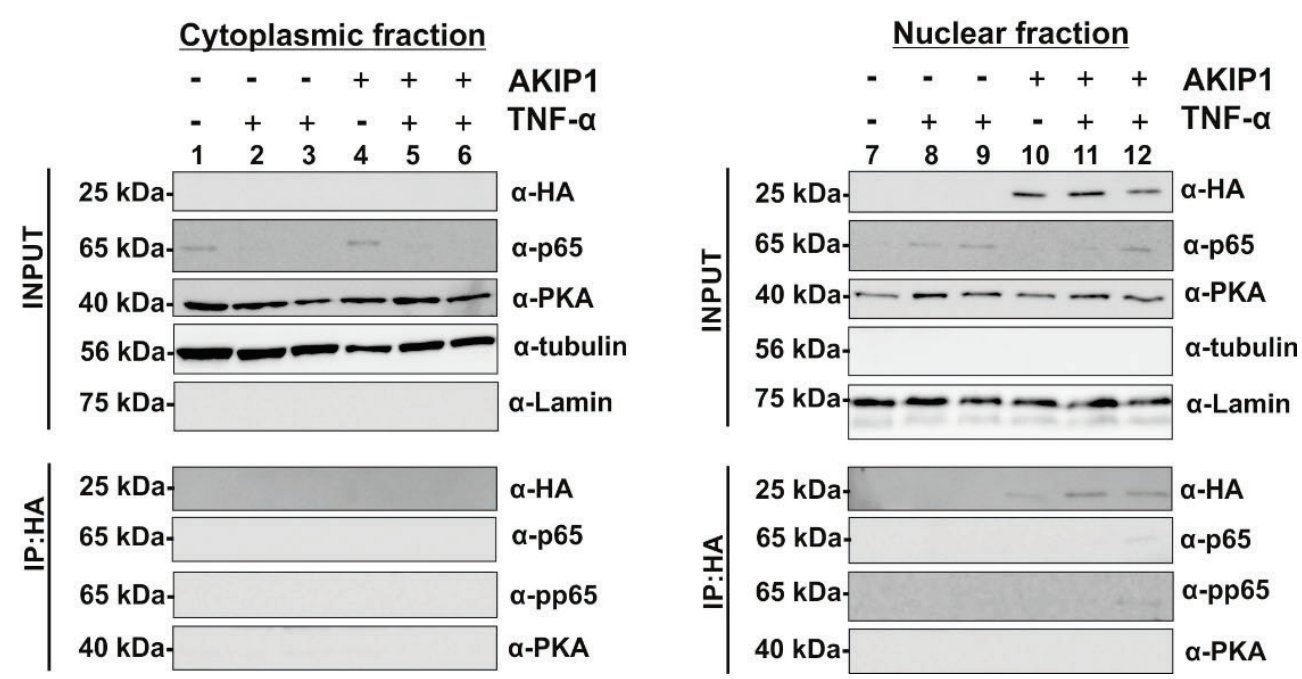

Fig. 6. Interaction of highly and lowly expressed AKIP1 with p65, phosphorylated p65 (pp65) and PKAc. HEK-293 cells transfected with pCM-VHA-AKIP1 expressing HA-AKIP1 at high level (A) and stably-transfected HEK-293 cell line expressing low level of AKIP1 (B) were left unstimulated or stimulated with TNF-a $(20 \mathrm{ng} / \mathrm{ml})$. Both cytoplasmic and nuclear fractions, prepared as described in Experimental procedures, were subjected to immunoprecipitation with anti-HA magnetic beads followed by Western blot analysis with indicated antibodies. 
Here, we show that an increasing amount of fulllength AKIP1 affected its subcellular localization (Figs 2 and 3). Highly expressed HA-AKIP1 in HEK-293 was found to be associated with mitochondria, but most of the proteins formed large, electron-dense aggregates in the nucleus and the cytoplasm. Although the mechanism of aggregate formation is still being discussed in the context of a wide variety of neurodegenerative diseases e.g. Alzheimer or Parkinson, it is still not clear how aggregates are generated in cells and whether other proteins are involved in their formation (Miyazaki et al. 2016). In Alzheimer disease for example mutated beta-amyloid protein aggregates either extracellularly into fibrous deposits or intracellularly into inclusions (Irvine et al. 2008). In Parkinson's disease, mutation driven misfolding of alpha-synuclein leads to its aggregation and deposition in Lewy bodies (Tan et al. 2009). In the organism, the protein misfolding can be prevented by cellular mechanisms involving chaperones and protein quality control systems as described e.g. for mutant androgen receptor namely expansion of the CAG triplet repeat causing spinal and bulbar muscular atrophy (Rusmini et al. 2016). In artificial tissue cultures systems, protein aggregation often results from their excessive overexpression. This applies particularly on hydrophobic proteins or those with hydrophobic surface domain. In contrast to bacterial inclusions, which consist usually of pure heterologous protein, deposits in mammalian cells are usually composed of a mixture of heterologous protein with cellular proteins. Interestingly, it has been published that this co-aggregation might be specific (Rajan et al. 2001). Moreover, at least part of the aggregates seem to be properly folded as indicated by presence of functional GFP domain in the fusion protein (Rajan et al. 2001). This is also the case of AKIP1 when it was fused either $\mathrm{N}$ - or C-terminally to GFP. Upon transient expression from the plasmids, both these AKIP1 GFP fusion proteins were observed as fluorescence aggregates in various intracellular locations (data not shown).
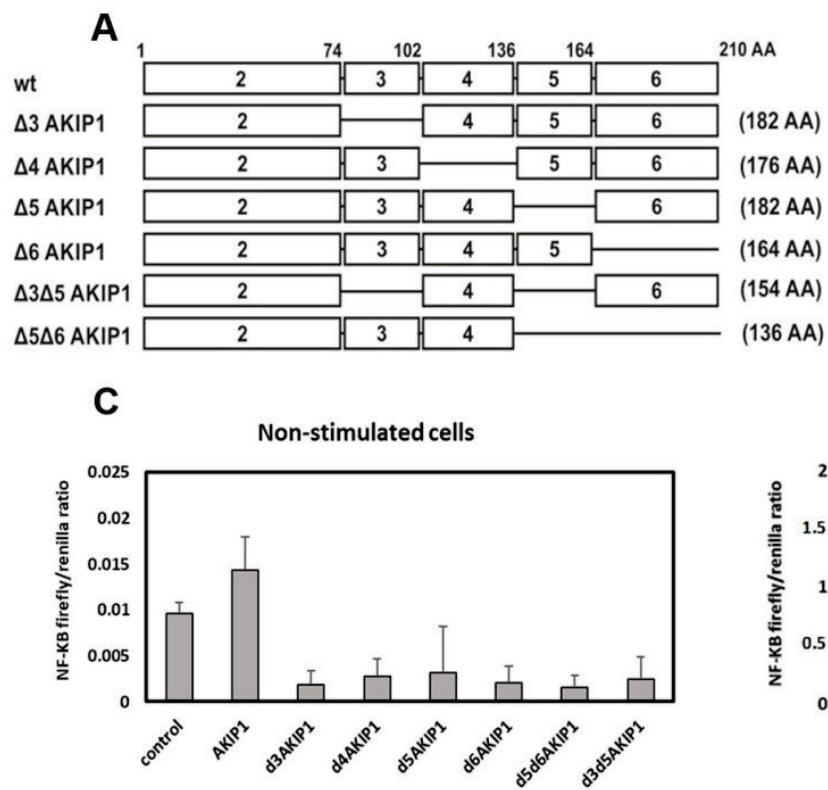
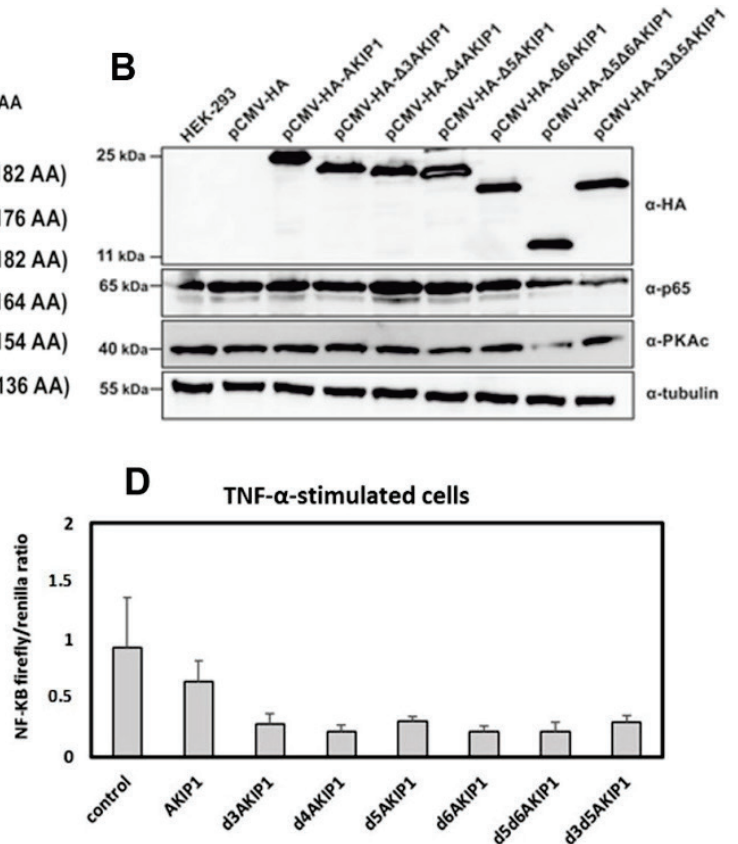

Fig. 7. The effect of HA-AKIP1 isoforms expression on NF-KB transcriptional activity. Schematic diagram of AKIP1 and its exon deletion variants is shown. (A) HEK-293 were transfected with vectors encoding HA-tagged AKIP1-truncated isoforms, and $24 \mathrm{~h}$ post transfection the cells were analyzed by Western blot using indicated antibodies. (B) non-transfected HEK-293 cells were used as control. HEK-293 transiently expressing AKIP1-truncated isoforms were co-transfected with NF-KB luciferase reporter system, unstimulated or stimulated with $20 \mathrm{ng} / \mathrm{ml} \mathrm{TNF-a}$, and $5 \mathrm{~h}$ later, the cell lysate was obtained for the dual-luciferase reporter assay (C, D). Data are expressed as the mean \pm SD from three independent experiments.

In contrast, lowly expressed HA-AKIP1 was localized in the nucleus without visible aggregation. The different AKIP1 localization most probably reflected the amount of cellular AKIP1 and illustrated the importance of proper experimental set up for relevant data. Nevertheless, neither highly nor lowly expressed AKIP1 enhanced NF- $\kappa \mathrm{B}$ activity. This finding contrasts with previous works by Zhang et al. (2014) or Gao et al. 
(2008), in which the same cell line (HEK-293) and the same dual reporter assay (DLR) were used and AKIP1 was expressed from a similar expression plasmid, pcDNA3.1-FLAG. The DLR assay, commonly used for the determination of activation of various transcription factors (TF), requires an internal control to normalize transfection efficiency of the vector carrying TF-response element. Usually, expression of Renilla luciferase is conveniently used. However, various conditions which can influence constitutive expression of Renilla luciferase and thus compromising the normalization process were reported (Shifera and Hardin 2010). Therefore, we generated stable HEK-293-NF-кB-GFP reporter cell line, in which GFP expression, driven by NF- $\mathrm{B}$ activation, is quantified by flow cytometry. Using this GFP-reporter HEK-293 cell line we confirmed that NF- $\kappa B$ transcriptional activity is not influenced in an AKIP1 dose-dependent manner. Although these data are in contrast with the findings by Gao et al. (2008) and Gao et al. (2010), they correlate with the data published by
Booij et al. (2016) who did not observe any AKIP1-induced effect on NF- $\kappa \mathrm{B}$ in transgenic mice overexpressing cardiac-specific AKIP1. Moreover, the presence of AKIP1 did not significantly alter the rate of I $\mathrm{B}$ degradation indicating that AKIP1 does not interfere with NF- $\kappa \mathrm{B}$ activation. A further investigation may provide important insight into understanding of AKIP1 functions in NF- $\kappa$ B pathway.

\section{Conflict of Interest}

There is no conflict of interest.

\section{Acknowledgements}

We thank Christina Ewald from University of Zurich for language corrections. This work was supported by the grants from the Ministry of Education of the Czech Republic, Youth and Sports of the Czech Republic: LTAUSA17061 to MR and NPU I LO 1302 from Ministry of Education of the Czech Republic to IP, and by the EU Horizon 2020 grant No 692195.

\section{References}

BOOIJ HG, YU H, DE BOER RA, VAN DE KOLK CW, VAN DE SLUIS B, VAN DEURSEN JM, VAN GILST WH, SILLJE HH, WESTENBRINK BD: Overexpression of A kinase interacting protein 1 attenuates myocardial ischaemia/reperfusion injury but does not influence heart failure development. Cardiovasc Res 111: 217-226, 2016.

GAO F, CHENG J, SHI T, YEH ETH: Neddylation of a breast cancer-associated protein recruits a class III histone deacetylase that represses NFkB-dependent transcription. Nat Cell Biol 8: 1171-1177, 2006.

GAO N, ASAMITSU K, HIBI Y, UENO T, OKAMOTO T: AKIP1 enhances NF-kappaB-dependent gene expression by promoting the nuclear retention and phosphorylation of p65. J Biol Chem 283: 7834-7843, 2008.

GAO N, HIBI Y, CUENO M, ASAMITSU K, OKAMOTO T: A-kinase-interacting protein 1 (AKIP1) acts as a molecular determinant of PKA in NF-kappaB signaling. J Biol Chem 285: 28097-28104, 2010.

GILMORE TD: Introduction to NF-kappaB: players, pathways, perspectives. Oncogene 25: 6680-6684, 2006.

HAYDEN MS, GHOSH S: Shared principles in NF-kappaB signaling. Cell 132: 344-362, 2008.

IRVINE GB, EL-AGNAF OM, SHANKAR GM, WALSH DM: Protein aggregation in the brain: the molecular basis for Alzheimer's and Parkinson's diseases. Mol Med 14: 451-464, 2008.

KING CC, SASTRI M, CHANG P, PENNYPACKER J, TAYLOR SS: The rate of NF-kappaB nuclear translocation is regulated by PKA and A kinase interacting protein 1. PloS One 6: e18713, 2011.

KITCHING R, LI H, WONG MJ, KANAGANAYAKAM S, KAHN H, SETH A: Characterization of a novel human breast cancer associated gene (BCA3) encoding an alternatively spliced proline-rich protein. Biochim Biophys Acta 1625: 116-121, 2003.

KRIZOVA I, HADRAVOVA R, STOKROVA J, GUNTEROVA J, DOLEZAL M, RUML T, RUMLOVA M, PICHOVA I: The G-patch domain of Mason-Pfizer monkey virus is a part of reverse transcriptase. J Virol 86: 1988-1998, 2012.

LANGEROVÁ H, RUML T, RUMLOVÁ M: Optimized method for isolation of immature intracytoplasmic retroviral particles from mammalian cells. J Virol Methods 248: 19-25, 2017.

LEUNG TH, NGAN HY: Interaction of TAp73 and breast cancer-associated gene 3 enhances the sensitivity of cervical cancer cells in response to irradiation-induced apoptosis. Cancer Res 70: 6486-6496, 2010. 
MIYAZAKI Y, MIZUMOTO K, DEY G, KUDO T, PERRINO J, CHEN LC, MEYER T, WANDLESS TJ: A method to rapidly create protein aggregates in living cells. Nat Commun 7: 11689, 2016.

RAJAN RS, ILLING ME, BENCE NF, KOPITO RR: Specificity in intracellular protein aggregation and inclusion body formation. Proc Natl Acad Sci U S A 98: 13060-13065, 2001.

RUMLOVÁ M, KŘIZŽOVÁ I, HADRAVOVÁ R, DOLEŽAL M, STROHALMOVÁ K, KEPROVÁ A, PICHOVÁ I, RUML T: Breast cancer-associated protein--a novel binding partner of Mason-Pfizer monkey virus protease. J Gen Virol 95: 1383-1389, 2014a.

RUMLOVÁ M, KŘÍŽOVÁ I, KEPROVÁ A, HADRAVOVÁ R, DOLEŽAL M, STROHALMOVÁ K, PICHOVÁ I, HÁJEK M, RUML T: HIV-1 protease-induced apoptosis. Retrovirology 11: 37, $2014 \mathrm{~b}$.

RUMLOVÁ M, KŘÍŽOVÁ I, ZELENKA J, WEBER J, RUML T: Does BCA3 play a role in the HIV-1 replication cycle? Viruses 10: 212, 2018.

RUSMINI P, CRIPPA V, CRISTOFANI R, RINALDI C, CICARDI ME, GALBIATI M, CARRA S, MALIK B, GREENSMITH L, POLETTI A: The role of the protein quality control system in SBMA. J Mol Neurosci 58: 348-364, 2016.

SASTRI M, BARRACLOUGH DM, CARMICHAEL PT, TAYLOR SS: A-kinase-interacting protein localizes protein kinase A in the nucleus. Proc Natl Acad Sci U S A 102: 349-354, 2005.

SASTRI M, HAUSHALTER KJ, PANNEERSELVAM M, CHANG P, FRIDOLFSSON H, FINLEY JC, NG D, SCHILLING JM, MIYANOHARA A, DAY ME, HAKOZAKI H, PETROSYAN S, KOLLER A, KING CC, DARSHI M, BLUMENTHAL DK, ALI SS, ROTH DM, PATEL HH, TAYLOR SS: A kinase interacting protein (AKIP1) is a key regulator of cardiac stress. Proc Natl Acad Sci U S A 110: E387-E396, 2013.

SHIFERA AS, HARDIN JA: Factors modulating expression of Renilla luciferase from control plasmids used in luciferase reporter gene assays. Anal Biochem 396: 167-172, 2010.

TAN JM, WONG ES, LIM KL: Protein misfolding and aggregation in Parkinson's disease. Antioxid Redox Signal 11: 2119-2134, 2009.

YAO C, YU KP, PHILBRICK W, SUN BH, SIMPSON C, ZHANG C, INSOGNA K: Breast cancer-associated gene 3 interacts with Rac1 and augments NF- $\mathrm{KB}$ signaling in vitro, but has no effect on RANKL-induced bone resorption in vivo. Int J Mol Med 40: 1067-1077, 2017.

ZHANG Y, HU MY, QIAO CX, FENG JN, LIN Z, SHEN BF, MA YF, LI Y, LI YL, LV M: Cloning and functional identification of a novel BCA3 splice. Genet Mol Res 13: 10648-10656, 2014. 